\title{
MUSHROOM POISONING: RETROSPECTIVE ANALYSIS OF 294 CASES
}

\author{
Sevki Hakan Eren, ${ }^{\text {I } Y e l t e k i n ~ D e m i r e l, ~}{ }^{\text {II }}$ Serdal Ugurlu, ${ }^{\text {III }}$ Ilhan Korkmaz, ${ }^{\text {I Can Aktas, }}{ }^{\text {IV }}$ Fatma Mutlu Kukul Güven
}

doi: $10.1590 / \mathrm{S} 1807-59322010000500006$

Eren SH, Demirel Y, Serdal U, Can A, Korkmaz I, Güven FMK. Mushroom poisonıng: retrospectıve analysıs of 294 cases. Clinics. 2010;65(5):491-6.

OBJECTIVE: The objective of this study was to present special clinical and laboratory features of 294 cases of mushroom poisoning. MATERIALS AND METHODS: In this retrospective study, 294 patients admitted to the Pediatric and Adult Emergency, Internal Medicine and ICU Departments of Cumhuriyet University Hospital were investigated.

RESULTS: Of 294 patients between the ages of 3 and $72(28.97 \pm 19.32), 173$ were female, 121 were male and 90 were under the age of 16 years. One hundred seventy-three patients $(58.8 \%)$ had consumed the mushrooms in the early summer. The onset of mushroom toxicity symptoms was divided into early (within $6 \mathrm{~h}$ after ingestion) and delayed (6 h to $20 \mathrm{~d}$ ). Two hundred eightyeight patients $(97.9 \%)$ and six $(2.1 \%)$ patients had early and delayed toxicity symptoms, respectively. The onset of symptoms was within two hours for 101 patients $(34.3 \%)$. The most common first-noticed symptoms were in the gastrointestinal system. The patients were discharged within one to ten days. Three patients suffering from poisoning caused by wild mushrooms died from fulminant hepatic failure.

CONCLUSION: Education of the public about the consumption of mushrooms and education of health personnel working in health centers regarding early treatment and transfer to hospitals with appropriate facilities are important for decreasing the mortality.

KEYWORDS: Mushroom; Poisoning; Emergency service; Intensive care unit.

\section{INTRODUCTION}

Various types of wild mushrooms grow in forests and meadows, and it is common for the local population to consume them. ${ }^{1}$ It is estimated that there are over 5000 species of mushrooms worldwide. Only 20-25\% of mushrooms have been named, and $3 \%$ of these are poisonous. ${ }^{2}$ Previous experience and observation make it possible to discriminate between poisonous and nonpoisonous mushrooms. ${ }^{1}$ Mushroom poisoning constitutes

\footnotetext{
${ }^{\text {I }}$ Department of Emergency Medicine, Cumhuriyet University Medical Faculty - Sivas, Turkey.

II Department of Family Medicine, Cumhuriyet University Medical Faculty - Sivas, Turkey.

III Division of Rheumatology, Department of Medicine, Cerrahpasa Medical Faculty, University of Istanbul - Istanbul, Turkey.

${ }^{\mathrm{VI}}$ Department of Emergency Medicine, Yeditepe University Medical Faculty - Istanbul, Turkey.

Email: shakaneren@hotmail.com

Received for publication on January 06,2010

First review completed on February 23, 2010

Accepted for publication March 05, 2010
}

the main portion of plant toxicities in Turkey. In addition to occurring in rural areas, gathering of mushrooms is a habit in Istanbul among villagers who have moved to the city and settled in the vicinity of a forest. ${ }^{3}$ During the fouryear period from 1994 to 1998 in Sivas, Turkey, mushroom poisoning represented $10.9 \%$ of the different analyzed poisonings. ${ }^{4}$ However, these cases were not analyzed toxicologically.

Depending on the type of mushroom, the adverse effects range from mild gastrointestinal (GI) symptoms to major cytotoxic effects resulting in organ failure and death. Toxicity may also vary depending on the amount and age of the mushroom, the season, the geographic location and the way in which the mushroom was prepared prior to ingestion. Consumption of poisonous mushrooms can cause various types of reactions, such as allergic gastroenteritis, psychological relaxation and fatal liver intoxication. ${ }^{1,5,6}$ Mushroom poisoning occurs among four main groups of individuals: young children who ingest mushrooms inadvertently, wild-mushroom foragers, individuals attempting suicide or homicide and individuals looking for a 
hallucinatory high. Identification of the ingested mushroom can be difficult and time consuming. In all cases, treatment should be directed by the patient's symptoms rather than by attempts at mushroom identification. ${ }^{6}$

Today, emergency department physicians have increasing occasions to treat mushroom poisoning. Interest in eating mushrooms has risen dramatically in recent years as part of the back-to-nature and organic food movement. In addition, some people are eating certain mushrooms for their hallucinogenic components, leading to an increase in mushroom poisonings. ${ }^{7}$

This study's aim was to determine the demographic and clinical features of adult and pediatric patients who were admitted to the hospital (ED) due to mushroom poisoning, and to emphasize the significance of mushroom poisoning. We contribute one of the largest series to be applied to the same hospital concerning mushroom poisoning, which has been seen frequently in developing countries and will increase in developed countries due to the rise of natural nutrition. Furthermore, to establish this study as the largest serial study concerning mushroom poisoning in Turkey, we will present extensive information about mushroom poisonings in our country.

\section{MATERIALS AND METHODS}

A retrospective descriptive/epidemiologic study was designed, and all patients with mushroom poisoning admitted to the Pediatric and Adult Emergency, Internal Medicine and ICU departments in the Cumhuriyet University Hospital in Sivas between 2000 and 2007 were studied. Two hundred ninety-four patients with mushroom poisoning were included in the study. We collected data on the season and location where the mushrooms were picked, method of cooking, symptoms, onset time for symptoms, laboratory findings, type of treatment administered and results of therapies. The laboratory evaluation included blood glucose, bilirubin, liver function, complete blood cell count, coagulation profile, electrolyte and renal function tests. Diagnosis was made according to the physical features of the mushrooms, time of appearance of symptoms, clinical conditions of the patients and laboratory parameters. The mushrooms toxins could not be analyzed. The onset times of mushroom toxicity symptoms were divided into early (within $6 \mathrm{~h}$ after ingestion) and delayed (6 h to 20 d). Patients with early symptoms were treated by stomach irrigation, the maintenance of the fluid-electrolyte balance, forced diuresis and the administration of activated charcoal, whereas patients with severe toxicity symptoms were treated by adding crystallized penicillin. In patients with fulminant hepatic failure, maintenance therapy was given, but liver transplantation could not be performed. Data are presented as the mean (SD) or percentage.

All data were analyzed with SPSS software, version 16.0. A detailed multiple-variable database was formed. Statistical comparisons were carried out using the Mann-Whitney U-test and Student's t -test. The Pearson test was used to evaluate correlations among variables. $\mathrm{P}$ values of 0.05 or less were considered to be statistically significant.

\section{RESULTS}

Two hundred ninety-four patients aged between three and seventy-two years $(28.97 \pm 19.32)$ were studied. Of these, 204 (69.4) were adults, and 90 (30.6\%) were in the pediatric age group. In the adult group, 121 patients were female, and 83 were male. In the pediatric group, 52 patients were female, and 38 were male. It was established that $173(58.8 \%)$ patients had consumed the mushrooms in the early summer, $84(28.6 \%)$ in the spring, $22(7.5 \%)$ in the autumn and $15(5.1 \%)$ in the winter. Two hundred seventy-six $(93.8 \%)$ patients had foraged for the mushrooms in nature (hills, riverbanks, fields), and eighteen $(6.2 \%)$ had bought cultivated mushrooms. The methods of cooking were as follows: the mushrooms were grilled by $112(38.1 \%)$ patients, roasted by $78(26.5 \%)$, cooked into the meal by $45(15.3 \%)$ and consumed uncooked by 59 (20.1\%). In total, $112(38.1 \%)$ patients were seen in the emergency care unit, $59(20.1 \%)$ in the internal service, $33(11.2 \%)$ in the intensive care unit and $90(30.6 \%)$ in the pediatric service.

Laboratory abnormalities were found in 112 (38.1\%) patients and included hematological abnormalities (leukocytosis, thrombocytopenia, prolonged prothrombin time), elevated liver enzymes, hematuria, glucosuria, impaired renal functions, hyponatremia, hypernatremia and hypoglycemia (Table 1).

Two hundred eighty-eight $(97.9 \%)$ patients had early and six $(2.1 \%)$ had delayed toxicity symptoms. The onset of symptoms was within two hours for 101 (34.3\%) patients. The signs and symptoms included cardiovascular, gastrointestinal and central nervous system symptoms (Table 2). In both adult and pediatric groups, the most common first symptom was nausea and vomiting $(84.8 \%$ and $78.8 \%$, respectively) (Table 3 ).

One hundred seventy-seven $(60.2 \%)$ patients were treated by stomach irrigation and the administration of activated charcoal. One hundred eleven $(37.7 \%)$ patients who had severe clinical manifestations were treated with stomach irrigation as well as administration of activated charcoal and penicillin G. Six patients $(2.1 \%)$ rejected therapy.

Four patients were pregnant. Neither the mothers nor the fetuses showed any problems. All of the patients were 
Table 1 - Laboratory data.

\begin{tabular}{|c|c|c|}
\hline Variables & Adult (n=204) & Pediatric $(n=90)$ \\
\hline Elevated WBC, $(>12000 \mathrm{U} / \mathrm{L})$ & $37(18.1)$ & $34(37.8)$ \\
\hline Thrombocytopenia, $(<100000$ U/L) & $2(0.9)$ & $1(1.1)$ \\
\hline $\mathrm{PT}(\mathrm{s}),(>17)$ & $7(3.4)$ & $4(4.4)$ \\
\hline $\operatorname{PTT}(\mathrm{s}),>40$ & $6(2.9)$ & $4(4.4)$ \\
\hline ALT (U/L), 40-100 & $11(5.4)$ & $1(1.1)$ \\
\hline $100-400$ & $3(1.5)$ & $1(1.1)$ \\
\hline$>400$ & $3(1.5)$ & $1(1.1)$ \\
\hline $\operatorname{AST}(\mathrm{U} / \mathrm{L}), 40-100$ & $15(7.4)$ & $1(1.1)$ \\
\hline $100-400$ & $3(1.5)$ & $0(0)$ \\
\hline$>400$ & $3(1.5)$ & $1(1.1)$ \\
\hline Bilirubin Total (mg/dl), (> 1) & $5(2.5)$ & $1(1.1)$ \\
\hline BUN (mg/dl), (40-100) & $6(2.9)$ & $1(1.1)$ \\
\hline Creatinine (mg/dl), 1-3 & $17(8.3)$ & $1(1.1)$ \\
\hline$>3$ & $1(0.5)$ & $0(0)$ \\
\hline $\begin{array}{l}\text { Microscopic hematuria, }\left(>50 / \mathrm{mm}^{3}\right. \\
\text { erythrocyte) }\end{array}$ & $4(1.9)$ & $0(0)$ \\
\hline Hyponatremia & $10(4.9)$ & $4(4.4)$ \\
\hline Hypernatremia & $2(0.9)$ & $0(0)$ \\
\hline Hyperglycemia (> 200 mg/dl ) & $6(2.9)$ & $6(6.6)$ \\
\hline Glucosuria & $5(2.5)$ & $0(0)$ \\
\hline
\end{tabular}

ALT: Alanine aminotransferase, AST:Aspartate aminotransferase PT:Protrombintime

PTT:Activated Parsiyel tromboplastin time BUN:Blood Urea Nitrogen

discharged within one to ten days. However, three patients (child=1, adult=2) who consumed raw mushrooms and were treated in the ICU died due to acute hepatic failure (Table 4). The mortality rate was $1.02 \%$. There was a significant $(\mathrm{p}<0.001)$ relationship between mortality, hepatic failure and consuming raw mushrooms.

\section{DISCUSSION}

Mushroom poisoning presents a major health risk in rural areas. It is estimated that there are over 5000 species of mushroom worldwide. ${ }^{2}$ Foraging for wild mushrooms is popular in Europe, the United States and the Far East. ${ }^{8-12}$ The exact identification of mushroom species can be difficult. Substantial morphologic variations can occur in the same mushroom species depending on the season, geographic location and maturity of the fungus. Most ingested mushrooms are either nontoxic or only gastrointestinal irritants, resulting in mild to moderate toxic effects. ${ }^{13}$

The pathogenicity of mushrooms depends on cyclopeptide toxins. The type of mushroom is unknown in $>90 \%$ of cases of digestion. ${ }^{5,14}$ Amatoxins, which account for $90 \%$ of fatal mushroom poisonings, have their most significant impact on the liver. ${ }^{15}$

Mushroom poisonings occur every year between June and December. ${ }^{16}$ A study performed in Japan reported that mushroom poisoning happened most frequently in September and October. ${ }^{17}$ A similar study performed in
Table 2 - Signs and symptoms of poisoning.

\begin{tabular}{|c|c|c|}
\hline Variables & Adult $(n=204)$ & Pediatric $(n=90)$ \\
\hline Nausea/vomiting & $173(84.8)$ & $71(78.8)$ \\
\hline Fatigue & $78(38.2)$ & $0(0)$ \\
\hline Abdominal pain & $65(31.9)$ & $16(17.8)$ \\
\hline Dizziness & $62(30.4)$ & $21(23.3)$ \\
\hline Diarrhea & $52(25.5)$ & $10(11.1)$ \\
\hline Headache & $35(17.29)$ & $5(5.5)$ \\
\hline Loss of consciousness & $34(16.6)$ & $20(22.2)$ \\
\hline Bradycardia & $27(13.2)$ & $1(1.1)$ \\
\hline Hyperthermia $\left(>37^{\circ} \mathrm{C}\right)$ & $20(9.8)$ & $0(0)$ \\
\hline Hypotension $(<80 \mathrm{mmHg}$ / systolic $) \dagger$ & $17(8.3)$ & $1(1.1)$ \\
\hline Tachycardia & $15(7.4)$ & $18(20)$ \\
\hline Mouth drying & $14(6.9)$ & $1(1.1)$ \\
\hline Myosis & $13(6.4)$ & $0(0)$ \\
\hline Blurred vision & $12(5.9)$ & $4(4.4)$ \\
\hline Dyspnea & $10(4.9)$ & $0(0)$ \\
\hline Tremor & $9(4.4)$ & $2(2.2)$ \\
\hline Mydriasis* & $8(3.9)$ & $0(0)$ \\
\hline Pruritus & $7(3.4)$ & $0(0)$ \\
\hline Urticaria & $6(2.9)$ & $0(0)$ \\
\hline Sweating & $6(2.9)$ & $2(2.2)$ \\
\hline Agitation & $5(2.5)$ & $6(6.6)$ \\
\hline Convulsion & $5(2.5)$ & $2(2.2)$ \\
\hline Hypertension (> $160 \mathrm{mmHg}$ / systolic) & $4(1.9)$ & $0(0)$ \\
\hline Arrhythmia & $3(1.5)$ & $0(0)$ \\
\hline Absence of light reflex & $2(0.9)$ & $0(0)$ \\
\hline Cyanosis & $2(0.9)$ & $0(0)$ \\
\hline Tongue edema & $2(0.9)$ & $0(0)$ \\
\hline Diplopia & $1(0.5)$ & $1(1.1)$ \\
\hline Nosebleed & $0(0)$ & $1(1.1)$ \\
\hline
\end{tabular}

*After atropine for two patients. $†$ Systolic blood pressure $<60 \mathrm{mmHg}$ for three patients

Table 3 - First symptoms of poisoning.

\begin{tabular}{lcc}
\hline Variables & Adult $(\mathrm{n}=204)$ & Pediatric $(\mathrm{n}=90)$ \\
\hline Nausea/vomiting, n (\%) & $131(64.2)$ & $67(74.4)$ \\
Dizziness, n (\%) & $22(9.8)$ & $11(12.2)$ \\
Abdominal pain, n (\%) & $18(8.8)$ & $4(4.4)$ \\
Blurred vision, n (\%) & $8(3.9)$ & $2(2.2)$ \\
Headache, n (\%) & $8(3.9)$ & $0(0)$ \\
Loss of consciousness, n (\%) & $7(3.4)$ & $3(3.3)$ \\
Diarrhea, n (\%) & $3(1.5)$ & $2(2.2)$ \\
Urticaria, n (\%) & $6(2.9)$ & $0(0)$ \\
Convulsion, n (\%) & $0(0)$ & $1(1.1)$ \\
Pruritus & $1(0.5)$ & $0(0)$ \\
\hline
\end{tabular}

ran reported that mushroom poisoning usually happened in autumn and spring. ${ }^{18}$ Unluoglu et al. reported that mushroom poisoning cases were seen in the spring or early summer. ${ }^{19}$ Ergüven et al. reported that mushroom poisoning cases were seen in the autumn. ${ }^{20}$ Another study performed in Turkey 
Table 4 - Laboratory parameters of deceased patients.

\begin{tabular}{lcccccccc}
\hline & Age (y) & ALT (U/L) & AST (U/L) & PT (s) & PTT (s) & $\begin{array}{c}\text { Platelet (U/L) Bilirubin (mg/ BUN (mg/dl) } \\
\text { dl) }\end{array}$ & $\begin{array}{c}\text { Creatinine } \\
(\mathrm{mg} / \mathrm{dl})\end{array}$ \\
\hline Case 1 & 45 & 2075 & 2345 & 50 & 62 & 16900 & 10.4 & 58 \\
Case 2 & 50 & 2754 & 2890 & 68 & 56 & 61900 & 12.8 & 42 \\
Case 3 & 13 & 3464 & 4048 & 120 & 94 & 32000 & 18.4 & 25 \\
\hline
\end{tabular}

ALT: Alanine aminotransferase, AST:Aspartate aminotransferase PT:Protrombintime

PTT:Activated Parsiyel tromboplastin time BUN:Blood Urea Nitrogen

reported that mushroom poisoning usually happened in October and November. ${ }^{21}$

In our study, $58.8 \%$ of the patients consumed the mushrooms in the early summertime. While the winter is very long and the rains start in May and June, mushroom collecting is increased during these months, and mushroom poisonings were seen at this time in Sivas. A seasonal variation was also seen in the present study that is consistent with the characteristics of the seasons, i.e., it rains during the spring, when mushrooms are prevalent.

Mushroom poisoning is caused not only by toxic mushrooms (true intoxications) but also, under certain conditions, by edible mushrooms (false intoxications and pseudo-intoxications). ${ }^{22}$ In our study, most of the mushroom poisonings were due to the consumption of foraged mushrooms, but $6.2 \%$ arose from commercially cultivated mushrooms. In another study, $5.6 \%$ of the patients were poisoned with cultivated mushrooms. ${ }^{19} \mathrm{~A}$ two-year survey conducted by the Food and Drug Administration showed that $21 \%$ of cultivated mushrooms were contaminated with toxic look-alike species. ${ }^{23}$

Cultivated mushroom poisoning did not result in adverse outcomes in our study. This shows that sanitation and hygienic conditions are inadequate during mushroom production.

Many preparation methods were used for the mushrooms before ingestion. In our study, grilling $(38.1 \%)$ and roasting (26.5\%) of the mushrooms were the most common. The toxicity may vary based on the amount ingested and the way in which the mushroom was prepared prior to ingestion. The cooking of wild mushrooms was relatively safe. Raw mushroom ingestion was very dangerous. In our study, the three patients who died from mushroom poisoning had ingested the mushrooms raw. Children are especially susceptible to this risky endeavor. They can easily find mushrooms in nature and eat them without cooking. Families must be careful to prevent accidental mushroom ingestion among children.

Clinically, mushroom toxicity is divided into early (within $6 \mathrm{~h}$ after ingestion) and delayed $(6 \mathrm{~h}$ to $20 \mathrm{~d}) .^{5} \mathrm{In}$ our study, most of the patients (97.9\%) had early toxicity symptoms. Only $2.1 \%$ of the patients had delayed toxicity symptoms. The most common first-noticed symptoms were gastrointestinal. A total of $37.7 \%$ of the patients had laboratory abnormalities. Alterations in hematological parameters and elevated transaminase levels were the most common laboratory findings. A considerable portion of amatoxin is taken up by hepatocytes, excreted into the bile and reabsorbed by the enterohepatic cycle. ${ }^{24,25}$ The amatoxins bind to RNA polymerase II and thus inhibit the hepatic formation of mRNA. ${ }^{26}$ As a result of this, Amanita species cause increases of AST(Aspartate aminotransferase) and ALT(Alanine aminotransferase) levels in the serum. ${ }^{27}$

Pajoumand et al. showed increases in ALT and AST levels in 17 of 25 patients. ${ }^{18}$ In another study examining 6317 cases, an increase in transaminase levels was reported for $0.5 \%$ of the patients. ${ }^{28}$ In the present study, $8.1 \%$ of the cases were found to have increased levels of AST and ALT. The patients who died had very high AST and ALT levels, with AST values between 2075-3464 U/L and ALT values between 2345-4048 U/L. As the AST and ALT values rose, hepatic coma followed. There was a significant relationship between mortality and liver enzyme levels (AST, ALT). This indicates that liver enzyme levels (AST, ALT) are a good prognostic marker of mushroom poisoning or an indication for liver transplantation.

Because the goal of the total prevention of mushroom poisoning is likely never to be reached, it is important for clinicians to focus on diagnosis and treatment. The diagnosis of mushroom poisoning must at least be considered in patients with appropriate symptoms. The most common toxic symptoms recorded in this study's subjects, including nausea, vomiting, fatigue, abdominal pain, dizziness, diarrhea, headache and loss of consciousness, have also been reported in the literature. ${ }^{29,30}$

Most patients present with gastrointestinal symptoms. It is important to establish the latency period of symptoms after ingestion. Late toxicities (symptom onset $>6 \mathrm{hrs}$ after ingestion) are life-threatening due to liver and renal failure. Patients who have jaundice after an acute gastrointestinal episode are suspected to be poisoned with amatoxins. Symptoms of mushroom poisonings with amatoxins begin 
at six to twenty-four hours after the initial ingestion of the mushroom. ${ }^{31,32}$ In our study, most of the mushroom-poisoned patients had early toxicity symptoms.

In total, $10.2 \%$ of our patients were discharged after 24 hours of admission, while $49.7 \%$ required hospitalization for 72 hours. According to the patients' symptoms and doctors' decisions, the patients were observed in the hospital for 24 hours to 72 hours. The patients who had no clinical manifestations or laboratory abnormalities were discharged from the hospital after the 24 hours of observation. Only $11.2 \%$ of the patients required intensive care unit admission. The patients who had delayed toxicity symptoms were required to undergo observation in the intensive care unit. The patients who had moderate clinical and laboratory findings were observed in the emergency observation unit. If a patient had no clinical and laboratory findings in 24 hours, they could be safely discharged from the hospital.

The patients who had histories of wild mushroom consumption were treated. The patients who had mild clinical symptoms were treated by stomach irrigation and the administration of activated charcoal, while those who had severe clinical manifestations were treated with stomach irrigation and the administration of activated charcoal in addition to penicillin G. The patients who had clinical symptoms from the cultivated mushrooms were treated symptomatically.

In this study, 294 patients with mushrooms poisoning, 3 of whom died (one child, two adults), were admitted to the Cumhuriyet University Hospital of the Faculty of Medicine in Sivas between 2000 and 2007. The mortality rate in this study was $1.02 \%$. Unluoglu et al. reported a mortality rate of $2.8 \% .{ }^{19}$ In another study in Turkey the mortality rate was $17.9 \% .{ }^{20}$ In a study in Istanbul the mortality rate was $21.4 \% .{ }^{20}$ The mortality rate of mushroom poisoning in Iran, one of our neighboring countries, was $12 \% .^{18}$ The low mortality rate in our study was due to early presentation to the hospital, early treatment by hemoperfusion and intoxication by species other than Amanita. An additional reason could be that the wild mushrooms in our region were less poisonous.

Mushroom poisoning is a public health problem. People and health care providers must be educated about this poison. The species of mushrooms are numerous, and there are various clinical presentations depending on the ingested species. There are no guidelines about the treatment of mushroom toxicity in the emergency department, so diagnosis and treatment must be based on the history of ingestion and associated clinical presentations. Patients showing delayed toxicity symptoms should be observed in intensive care units. Despite treatment, the prognosis can be mortal. These types of patients must be transferred immediately to hospitals where liver transplantations can be performed. Children are a high-risk group for wild and uncooked mushroom poisonings.

\section{REFERENCES}

1. Mushroom poisoning. Lancet. 1980;2:351-2.

2. Gonmori K, Yoshioka N. The examination of mushroom poisoning at Akita University. Legal Medicine. 2003;5:83-6.

3. Oztekin-Mat A. Mushroom poisoning in Turkey. Ann Pharm Fr. 1998;56:233-5.

4. Alagözlü H, Sezer H, Candan F. A survey of patients with acute poisoning in the Sivas region. Turkey, between 1994 and 1998. Turk J Med Sci.2002;32:39-42.

5. Lin YM, Wang TL. Mushroom poisoning. Ann Disaster Med. 2004;3:811.

6. Schnider SM, Brayer A. Mushroom Poisoning. Tintinalli J, Kelen GD, Stapczynski JS (eds). Emergency Medicine. Acomprehensive Study Gide. McGraw-Hill 2000;5: 1317-22.

7. Rumack BH, Peterson RG. Diagnosis and Treatment of Mushroom Poisoning. Advanced Emergency Nursing Journal. 1979;1:85-96.

8. Barbee G, Berry CC, Barry J, Borys D, Ward J, Salyer S. Analysis of mushroom exposures in Texas requiring hospitalization, 2005-2006. J Med Toxicol. 2009;5:59-62.

9. Nordt SP, Manoguerra A, Clark RF. 5-Year analysis of mushroom exposures in California. West J Med. 2000;173:314-7.
10. Broussard CN, Aggarwal A, Lacey SR, Post AB, Gramlich T, Henderson JM, et al. Mushroom Poisoning-From Diarrhea to Liver Transplantation. AJG. 2001;96:3195-8.

11. Ishihara Y, Yamaura Y. Descriptive epidemiology of mushroom poisoning in Japan. Nippon Eiseigaku Zasshi. 1992;46:1071-8.

12. Barbato MP. Poisoning From Accidental Ingestion of Mushrooms. Med J Aust 1993; 158: 842-7.

13. Trestrail JH IIII. Mushroom poisoning in the United States: an analysis of 1989 United States Poison Center Data. J Toxicol Clin Toxicol. 1991;29:459-65.

14. Litovitz TL, Klein-Schwartz W, Caravati EM.: 1998 annual report of the American Association of Poison Control Centers toxic exposure surveillance system, Am J Emerg Med. 1999;17:435-87.

15. Barbato MP. Poisoning From Accidental Ingestion of Mushrooms. Med J. 1993;158:842-7.

16. Lapinski TW, Prokopowicz D. Epidemiological factors of mushroom poisoning in the north-east of Poland Przegl Epidemiol. 1998;4:463-7.

17. Ishihara Y, Yamaura Y. Descriptive epidemiology of mushroom poisoning in Japan. Nippon Eiseigaku Zasshi. 1992;46:1071-8. 
18. Pajoumand A, Shadnia S, Efricheh H, Mandegary A, HassanianMoghadam H, Abdollahi M. A retrospective study of mushroom poisoning in Iran. Hum Exp Toxicol. 2005;24:609-13.

19. Unluoglu I, Tayfur M. Mushroom Poisoning: An analysis of the data between 1996 and 2000. Eur J Emerg Med. 2003;10:23-6.

20. Ergüven M, Caki S, Deveci M. Mantar zehirlenmesi: 28 vakanın de erlendirilmesi. Turkish Pediatric Journal. 2004;47:249-53.

21. Deniz T, Saygun M. Investigation of 62 mushroom poisoning cases applied to the emergency service during one month period. Akademik Acil Tip Dergisi. 20 8 8;7:2 9-32.

22. Gavornik P. Prevention and treatment of mushroom poisoning. Vnitr Lek 1999; 3:193-6.

23. Gecan JS, Cichowicz SM. Toxic mushroom contamination of wild mushrooms in commercial distribution. J. Food. Protec. 1993;56:730-4.

24. Langer M, Gridelli B, Piccolo G, Markovic S, Quarenghi E, Gatti $\mathrm{S}$, et al. A liver transplant candidate (fulminant hepatic failure from Amanita phalloides poisoning) as a multiorgan donor. Transp. Proc. 1997;29:3343-4.
25. Cole FM. A puppy death and Amanita phalloides. Aust Vet Assoc. 1993;70:271-2.

26. Kroncke KD, Fricert G, Meier PJ, Gerok W, Wieland T, Kurz G. Alphaamanitin into hepatocytes. J Biol Chem. 1986;261:12562-7.

27. Kendrick B, Shimizu A. Mushroom poisoning - analysis of two cases, and a possible new treatment, plasmapheresis. Mycologia. 1984;76:44853.

28. Nordt SP. 5-Year analysis of mushroom exposures in California. West J Med. 2000; 173:314-7.

29. Haddad L, Winchester J. Clinical management of poisoning and drug overdose. Philadelphia: Saunders Co. 1998:365-74.

30. Droisbach RH, Robertson WO. Handbook of poisoning: prevention, diagnosis and treatment. California: Appleton \& Lange, 1987:504-7.

31. Pinson CW, Daya MR, Benner KG. Liver transplantation for severe Amanita pholloides mushroom poisoning. Am J Surg. 1990;159:493-9.

32. Kaufmann P. Mushroom poisonings: syndromic diagnosis and treatment. Wien Med Wochenschr. 2007;157:493-502. 